\title{
Will Work For Free: The Biopolitics of Unwaged Digital Labour
}

\author{
Brian A. Brown \\ University of Windsor, Windsor, Ontario, Canada, bbrown@uwindsor.ca
}

\begin{abstract}
This paper begins with a survey of the literature regarding a particular, yet ever more consequential and profitable, typology of digital labour: 'free labour' (Terranova, 2000, 2004), 'unwaged immaterial labour' (Brown and Quan Haase, 2012; Brown, 2013), and/or immaterial labour 2.0 (Coté \& Pybus, 2007), to name a few of the more common terms. It then moves on to proffer a critical synthesis of this body of work so as to conclude with a much more theoretically nuanced definition of unwaged digital labour than that which has thus far been provided. In sum, the author argues that there are five central facets to unwaged digital labour that defines and differentiates it from its waged brethren. The first is that unwaged digital labour is fundamentally and inherently autonomous. Free of management oversight, the cooperative and creative capacities of content-generators produce massive amounts of digital artefacts that in the majority of cases also yield massive amounts of profit for the owners of Web 2.0 sites and services. The surplus value produced by this first facet refracts into the second. Following the work of Fuchs $(2010,2011,2012,2013)$, unwaged digital labour is (in the majority of circumstances) hyper-exploited. As has been argued elsewhere (Brown, 2013), this hyperexploitation is the primary cause for recurrent 'user' uproar on Web 2.0 sites and services. This kind of exploitation, then, is met with the third facet of digital labour considered herein: resistance or struggle. Facile recourse to nebulous conceptions regarding the invasion of one's privacy on eminently social networks no longer suffices in explaining these instances of 'user' uproar. Thus, a more nuanced consideration of the forms of resistance that occur on social media sites and services is offered. Similar, yet different, to its waged genus, the fourth facet of unwaged digital labour is that it is intrinsically collaborative, cooperative, and generative of social relationships. The differences that obtain between the orientation of the social relationships constituted by waged and unwaged digital labour respectively are indicative of political potentials that have up until this point been under-theorized. Thus, building on the four aforementioned facets, as well as the arguments put forth by Hardt and Negri regarding the biopolitical dimensions of 'immaterial labour' $(2000,2004,2009)$, the fifth and most theoretically provocative facet is that this kind of labour is inspired, guided, and regulated by a radically different amalgam of biopolitical power relationships that point to the potentials of a commons-based political economy existing beyond the hyper-exploitative dimensions of capital.
\end{abstract}

Keywords: Unwaged Digital Labour, Free Labour, Immaterial Labour 2.0, New Media, Social Media, Autonomist Marxism, Biopolitics, Online Privacy.

\section{Introduction: The 6 Million Dollar A Day Man}

On November 7, 2013, Twitter, a wildly popular micro-blogging service that encourages its members to post one hundred and forty character status updates to a list of followers that sometimes numbers in the millions, filed its Initial Public Offering (IPO). In one of the most highly anticipated technology offerings to hit the open market in decades, shares in the micro-blogging service closed on the first day of trading at US $\$ 44.90$ yielding a valuation of roughly US $\$ 31$ billion. At the time of last revision (July 30, 2014), Twitter's share price is US\$46.62 with a market capitalization of US\$22.77 Billion. These massive valuations are particularly noteworthy in that Twitter "is unlikely to make a profit until 2015" (Frier and Picker 2013) and has yet to prove its mettle in terms of its ability to monetize the billions of tweets coursing through its servers every second of the day. These astronomical sums, however, are not without precedent.

In May 2012, Facebook, a social media behemoth founded by Mark Zuckerberg, brought itself to market and, in what is widely regarded as a botched IPO, was initially valued at 
roughly US $\$ 100$ billion. The stock declined precipitously in the coming weeks and months, but eventually rallied behind a new mobile advertising strategy and at the time of last revision is valued at $\$ 74.88$ per share with a market capitalization of US $\$ 194.69$ billion. As far as Facebook is concerned, this colossal sum positions the social media company as more valuable than General Motors and the Ford Motor Company combined. In a telling indication of the shifts in the production of wealth and profit in the contemporary era, Zuckerberg, Facebook's Chief Executive Officer (CEO), is reported to have made more than US\$6 million each and every day in fiscal 2012 (Rushe 2013).

Fewer than 6000 individuals around the world draw a pay packet from Facebook Inc. Once again, in comparison, Ford Motor Company employs roughly 180,000 individuals and General Motors 202,000 people (MacroAxis 2013). However, unlike these industrial giants, Facebook has managed to offload the vast majority of the heavy lifting that generates the profits accrued by them to their unwaged 1.23 billion active monthly 'users.' All of this labour, the work of generating content and posting it to their website, creating and maintaining networks, sharing images, stories, news, videos, sound clips, and personal thoughts is undertaken and accomplished free of the wage relation and, pivotally, free of any kind of management oversight or supervisory directive. Left to their own devices and free to do as much or as little labour as they desire, Facebook's 'users' have proven an inexhaustible source of content and thus of the profits that accrue as a result of leveraging the details of this content into advertising dollars-the primary source of Facebook's revenue.

Different scholars have conceptualized this kind of labour in a variety of manners. By far the most popular way of understanding all of this unwaged digital labour is via recourse to the critical political economy of communications and the work of Dallas Smythe (1977). This paper begins, then, with a critical examination of the ways in which scholars have described and characterized all of the unwaged labour taking place on what have variously been termed New Media sites and services, Web 2.0 sites and services (O'Reilly 2005), or Social Media websites.

One of the first to conceptualize all of the work taking place on Web 2.0 sites and services was Tiziana Terranova. Terranova describes all of the unwaged labour taking place on the Internet as a form of "Free Labor" (2000). Building on the work of Terranova and referencing the highly influential thoughts of Maurizzio Lazzarato and his conception of "Immaterial Labor" (1996), Mark Coté and Jennifer Pybus proffer "Immaterial Labour 2.0" as a typological descendent of Lazzarato's theorization of waged Immaterial Labour and Terranova's conception of Free Labor. Responding to the work of Smythe and the above authors, Nicole Cohen, in an article that has proven highly influential, focuses her critical sights on the "free labour" (2008) responsible for producing the profits generated by Facebook. Finally, Christian Fuchs $(2009,2010,2012,2013)$, one of the most vocal and astute critics of the 'free labour' thesis, argues via Marx's Labour Theory of Value (1976) that all of the work that goes into maintaining one's presence and profile on Web 2.0 sites and services can be considered exploitative in that in its absence, the companies would have to pay employees to generate an equal amount of content. Fuchs' contribution offers a much more theoretically nuanced definition of this concept that encapsulates many of the attributes identified in the aforementioned authors' work. As will be detailed below, what all of the above authors have in common is a consistent focus on the critical political economic dimensions of Web 2.0 and social media. This focus, however, while accurate and theoretically correct, overlooks an equally important definition of the typological distinctions that separate unwaged digital labour from its waged forebear. In what follows, then, I define "unwaged digital labour" via a five-faceted typological theorization that takes into account existing scholarship, but moves beyond it so as to define the concept's core characteristics in much more concrete terms.

The five facets of unwaged digital labour described below are as follows: i) its inherent autonomy, ii) its exploitative nature, iii) instances of resistance and struggle, iv) its intrinsically collaborative and cooperative nature, and v) its biopolitical impact on the constitution of subjectivity. By conceptualizing unwaged digital labour in this way, we gain an appreciation of the relatively unique and progressive political potentials of this form of directed action. This paper concludes by pointing to the influence of unwaged digital labour on the subjectivities of 
those that undertake and accomplish it and argues that without the biopolitical influence on the subjective orientation of unwaged digital labourers, social movements such as Occupy Wall Street or the (dis)organizational forms that inspired the halting 'Arab Spring' in Egypt, for instance, would never have come to pass. It is the inherent autonomy of this form of labour, combined with its biopolitical influence, which provided these social movements with nascent evidence of the viability of a form of leaderless organization that is, on the one hand, highly interconnected, collaborative and cooperative, at the same time as it is, on the other hand, heterarchical, fluid, and dynamic. By appreciating the progressive political potentials evinced by unwaged digital labour, we gain a more robust understanding of the modes of organization that are becoming ever more common in the struggle against capital. It is to a critical analysis of this relatively unique form of labour that the following pages are directed.

\section{2. 'Free' (Unwaged) [Immaterial/Digital] Labour \{2.0\}: Reviewing the Literature}

Nomenclature is important. The ways in which we name, describe, and characterize particular phenomena influence our understanding and critical appreciation of them. As the subheading of this section of the paper indicates, the nomenclatural contortions that have come to characterize our understanding of the subject at hand have been diverse. This paper settles upon and operationalizes the term "unwaged digital labour" to describe all of the "work" being done on Web 2.0 sites and services. It does so with the goal of conceptual clarity foremost in mind.

The first term in the phrase indicates that all of this labour goes "unwaged". In fact, as previous research has shown (Brown 2013), members of Web 2.0 sites and services undertake and accomplish this labour without any expectation of financial remuneration. The second term in the phrase is a more accurate description of the nature of this labour than the "immaterial" qualifier that so often gets attached to this form of directed action. Lastly, "labour" rather than "work" was chosen as a more suitable term in that it acknowledges Marx's "Labour Theory of Value" (1976) and the exploitative dimensions of this form of directed action. (See: Fuchs and Sevignani 2013). The choice of this phrase, however, did not arise in a vacuum. There is a long history of thinking through the various dimensions and instances of unwaged labour (Dalla Costa and James 1973, Wages For Housework 1988). In what follows, however, I will focus strictly on those authors that consider these ideas alongside networked modes of digitized communication.

Writing in an epoch that predated the rapid rise of "social media" and "user-generated content", Tiziana Terranova identified "Free Labor" (2000) as a central component of networked forms of communication and production. She was one of the first to conceptualize and try to better understand the implications of this "free labor" to the Internet. Terranova defines "free labor" as "Simultaneously voluntarily given and unwaged, enjoyed and exploited, free labor on the Net includes the activity of building Web sites, modifying software packages, reading and participating in mailing lists and building virtual spaces on MUDs [Multi-User Dungeon] and MOOs [Object Oriented MUD]" $(2000,33)$. She argues further that, "the Internet is animated by cultural and technical labor through and through, a continuous production of value that is completely immanent to the flows of the network society at large" $(2000,34)$. After assessing the productivity and efficiencies of this work, she argues that our understanding of what it means to labour cannot be myopically confined to that which is exchanged for a wage. She states categorically that "Labor is not equivalent to waged labor [...] [and to] emphasize how labor is not equivalent to employment also means to acknowledge how important free affective and cultural labor is to the media industry, old and new" (46). The point being that "free labor" must be considered as such in that it is not only temporally, affectively, and physically taxing, but it is also productive of enormous sums of profit for those that own the means through which it is monetized.

Projecting Terranova's argument into the Web 2.0 era of social media and user-generated content, and leaning on the work of Maurizzio Lazzarato and his conceptualization of waged "immaterial labour" (1996), Mark Coté and Jennifer Pybus (2007) choose the once dominant, 
but now in decline, social network of MySpace (and subsequently Facebook (Coté and Pybus 2011) as their object of study and posit "Immaterial Labour 2.0" as a significant and meaningful amendment to Terranova's and Lazzarato's "free (immaterial) labor" thesis. They argue that:

What the '2.0' addresses is the 'free' labour that subjects engage in on a cultural and biopolitical level when they participate on a site such as MySpace. In addition to the corporate mining and selling of user-generated content, this would include the tastes, preferences, and general cultural content constructed therein. $(2007,90)$

Immaterial labour 2.0 further blurs the already hazy distinction between labour time and leisure time identified as a primary outcome of the waged immaterial labour thesis initially offered by Lazzarato (1996) and further underscored by scholars like Berardi (2009), Turkle (2011), Hardt and Negri (2004), and Huws (2003). Broadly conceptualized as an instance of the 'real subsumption' (Marx 1975, Negri 1991) of subjectivity to the demands and dictates of a capitalist mode of production that reaches into evermore intimate and private spheres, Immaterial Labour 2.0 was a pivotal publication that helped clarify the terms of debate and elucidate the penetration of the capitalist relation into spaces and places previously undertheorized.

Coté and Pybus argue that on social networks such as MySpace, Facebook, or, by extension, Twitter, the work one does connecting with friends, sending messages or updates, linking to web pages, posting images, "liking" posts, products, and people, uploading songs, sharing, chatting, and socializing, is unquestionably productive of economic value for the owners of these social networks. Social Networks like MySpace and Web 2.0 archetypes such as Twitter are, then,

shaped by the creative imprints of [their] users. However, its political-economic foundation demonstrates how such user-generated content-immaterial labour 2.0-is the very dynamic driving new revenue streams. Thus, it is the tastes, preferences, and social narratives found in user entries which comprises the quotidian mother lode of these new revenue streams. (Coté and Pybus 2007, 100)

In this regard (and similar to the arguments made by Terranova above) Immaterial Labour 2.0 focuses on a critical political economic interpretation of all the work being done on Web 2.0 sites and services. All of this labour, while unwaged, is productive of profit and, thus, exploitative of those responsible for accomplishing it.

Nicole Cohen's work too falls into the critical political economic realm of theorizing unwaged digital labour. Taking Facebook as her central example, Cohen argues that Web 2.0 sites and services would simply not exist without an enthusiastic and highly motivated work force. According to Cohen:

By uploading photos, posting links, and inputting detailed information about social and cultural tastes, producer-consumers provide content that is used to generate traffic, which is then leveraged into advertising sales. [...] In this model, rather than employing workers to create content, Web 2.0 companies [...] profit from the unpaid labour time that producer-consumers spend working on their online identities and keeping track of their friends. $(2008,7)$

She continues later on in her article by referencing the autonomist Marxist conception of the social factory (Negri 1989) as a place where the aforementioned "real subsumption" of subjectivity takes place. "Facebook, a space where both leisure time is spent and labour performed, is an example of how, in the social factory, general social relations become moments of production" (Cohen 2008, 18).

While the above authors point to the exploitative relationship that exists between the owners of Web 2.0 sites and services, they have yet to adequately unpack this relationship in such a way that makes manifest this exploitation in terms of its applicability to Marx's Labour 
Theory of Value (1976). The work of Christian Fuchs supplements the above authors' contentions, then, via a close reading of Marx's original thoughts on exploitation and the ways in which the political economy of Web 2.0 meshes with them.

Fuchs argues his position via reference to the work not only of Marx but also Critical Communications Scholar Dallas Smythe and his concept of the 'audience commodity' (Smythe 1977). Smythe's work will be addressed in more detail below. For the time being, however, it is important to emphasize the exploitative dimensions of unwaged digital labour as Fuchs understands them. He argues:

The users who google data, upload or watch videos on YouTube, upload or browse personal images on Flickr, or accumulate friends with whom they exchange content or communicate online via social networking platforms like MySpace or Facebook, constitute an audience commodity that is sold to advertisers. The difference between the audience commodity on traditional mass media and on the Internet is that in the latter the users are also content producers [...] Advertisements on the Internet are frequently personalized; this is made possible by surveilling, storing, and assessing user activities with the help of computers and databases. This is another difference from TV and radio, which provide less individualized content and advertisements due to their more centralized structure. $(2009,31)$

The labour required to produce all of the content that populates Facebook or Twitter, for instance, is accomplished by a group of individuals who receive no compensation in exchange for this work. Indeed, because this labour goes unwaged and because it is also productive of massive amounts of profit, Fuchs argues, correctly, that this scenario can be described as hyper-exploitative or "one of infinite over-exploitation [...] an extreme form of exploitation" (2011, 298).

As the all-too-brief tour through the nomenclatural history of the unwaged digital labour debates indicates, there has been, from the beginning, a penchant to focus on its critical political economic aspects in tandem with its exploitative dimensions. While this emphasis is accurate and correct, the authors that expound its exploitative dimensions have yet to appreciate or take into consideration a number of other markers that distinguish unwaged digital labour from its historico-conceptual predecessors. In what follows, then, the exploitative conditions under which the vast majority of content generators operate are acknowledged, but a more rounded and nuanced version of this labour is also offered. This is done in an attempt to better conceptualize the place of unwaged digital labour within the current mode of capitalist globalization as well as to point to the manner in which it is also cracking the ahistorical veneer of the capitalist social relation. By doing so, this kind of unwaged labour is allowing some light to be shone on fundamentally autonomous modes of production that posit the faint possibility of one day eclipsing the exploitative dimensions of the wage relation. Even if ever so faint, this possibility requires that we further examine it and reflect upon its radical potential.

\subsection{Facet One: The Autonomy of Unwaged Digital Labour}

It is no coincidence that the theoretical lineage upon which much of the debate surrounding the unwaged digital labour thesis can be broadly described as sympathetic to the perspective provided by autonomist Marxist theory. Originating in Italy in the 1950s, autonomist theory is predicated on the argument that labour and capital are engaged in recurrent and everexpanding "cycles of struggle" (Dyer-Witheford 1999, 62-90) that mutate the composition and form of each party according to the offenses and defenses launched by their other. Catalyzing these cyclical struggles is the ever-present potential autonomy of labour in its relation to capital. That is, whereas capital is ultimately reliant on labour as its primary source of profit, autonomist theory argues that the inverse relation does not apply. While capital cannot survive without labour, labour is capable of organizing and managing its creative and productive capacities free of the capitalist social relation. In other words, "Capital, a relation of general commodification predicated on the wage relation, needs labor. But labor does not need capi- 
tal. Labor can dispense with the wage, and with capitalism, and find different ways to organize its own creative energies: it is potentially autonomous" (Dyer-Witheford 1999, 68). It is the persistent desire to organize these capacities autonomously and beyond the exploitative purview of the capitalist social relation that catalyzes the cyclical struggles between labour and capital. When considered from the perspective provided by unwaged digital labour, nowhere is the potential autonomy of labour more evident than on the self-managed and selforganized networks of Web 2.0 in general and social media in particular. It is for this reason that the perspective provided by autonomist theory is highlighted as the first facet of this theoretical framework.

Free of any kind of management oversight, unencumbered by supervisory directive, absent a structured work environment or duration, removed from the organizational forms so characteristic of hierarchical capitalist command and control, and, undeniably free of the wage relation, unwaged digital labourers devote prodigious amounts of time, energy, intellect, and affect to projects that have the capacity to harness the collective intelligence of a global network of content generators, working at all times of the day, and in every corner of the world. While the owners of Web 2.0 sites and services urgently rely on this globally distributed, yet interlinked, network of content generators, the inverse relation does not hold. This pivotal point is made clear by reference to one of the now ossified fossils of the Web 2.0 era-MySpace.

Rupert Murdoch's News Corporation purchased MySpace at its popular apogee in 2005 for an estimated US $\$ 580$ million (Rushe 2011). Six years later, and in the wake of a mass exodus from the site towards Facebook, News Corporation sold an emaciated MySpace for a paltry US $\$ 35$ million. This example points to the resolute dependence of high-technology capital on the surplus value produced by their unwaged digital labour force. However, it also points to the mobility and elemental autonomy of this same labour force, underscoring their autonomous and peripatetic nature.

The autonomous nature of labour is not unique to its unwaged digital variant. Free lancers and the self-employed, for instance, have some level of autonomy that resembles the autonomous nature of unwaged digital labour. Digital labourers, in general, have much more autonomy in their day-to-day activities than did industrial workers of the past for instance. However, there are two fundamental differences that distinguish the autonomy of unwaged digital labourers from waged digital labourers. The first is the complete and utter lack of a boss, manager, client, or supervisor in the social relations that constitute the work environment. The second is, as the terminology indicates, the absence of a wage.

In regards to the first, unlike waged digital labourers, unwaged digital labourers do not undertake a project, task, assignment, or job in response to the directive provided by a superior-whether that superior be a client, boss, or manager. Unwaged digital labourers work on projects they choose for themselves and in collaboration with a group of networked peers. Regarding the second, the absence of any kind of financial remuneration distinguishes unwaged digital labour from its waged variant. The lack of financial incentive in relation to the amount of labour taking place and the profits accrued is one of the most significant elements of unwaged digital labour that marks it as distinct from its waged other.

Importantly, the fundamental autonomy of unwaged digital labours does not extend into all areas of their existence. For instance, in order to do the labour they do on social networks, these individuals must have a source of income that provides them with the financial resources to purchase the hardware and software required to participate on these same networks. That is, they must exchange their labour for an incommensurate wage on the labour market with an institution that relies on exploiting this labour to turn a profit. And while the relative absence of autonomy in the waged labouring environment is, in a manner of speaking, prerequisite to labouring in the unwaged digital environment, the non-autonomous nature of one environment should not preclude appreciation of the autonomy evident in another.

More than capable of managing and organizing their own labour free from the structures of hierarchical control so characteristic of capitalist enterprise, this labour force assembles, disassembles, aggregates, and disaggregates according to popular whim and fancy. It merits mention, however, that as individual content generators devote more and more time and ef- 
fort to their particular plot of virtual land within a particular social network, the likelihood of them migrating to another platform diminishes as they become further and further tied, or "locked-in," to that domain. The diminishing potential for virtual migration is explained by the fact that if these individuals were to uproot themselves from Facebook's proprietary servers, for instance, the labour required to "start anew" on another plot would be substantial. However, acknowledging the potential of "lock-in" does nothing to negate the fundamental autonomy of this labour force in any way. Whether labouring on a proprietary, for-profit social network or, instead and perhaps, on a commons-based social network organized around an entirely different logic with an entirely different amalgam of social relations, the autonomy of the unwaged digital labour force is resolute.

As alluded to above, one of the most important aspects of the autonomy of unwaged digital labourers that differentiate them from their waged counterparts is the fundamental lack of hierarchical command and control characteristic of industrial or corporate environments. Instead of the chain of command dictating what gets produced, when, how, and where, unwaged digital labour is guided by a much more unstable form of organization. Axel Bruns (2008) argues that instead of hierarchy, projects that rely on a mode of "produsage" (Production + Usage) are organized along heterarchical lines. Rather than having a waged employee assigned to a determinate job and a fixed position within the corporate hierarchy that excludes all of his/her other potential contributions, within a heterarchical form of organization,

there is no prior formal filtering for participation, but rather [...] it is the immediate practice of cooperation which determines the level of expertise and level of participation. [This] does not deny 'authority,' but only fixed forced hierarchy, and therefore accepts authority based on expertise, initiation of the project, etc. (Bauwens, 2005 quoted in Bruns, 2007).

This authority is not based on a rigid model that fixes decision-making and directive in the body and mind of a single individual - the CEO or Supervisor, for instance. It is, rather, a temporary and amorphous form of authority, transferred from one person to the next, which responds to the idiosyncratic nature of the problem or task at hand by calling upon the aptitudes of those self-nominating individuals capable of helping to resolve it. The parallel between Bruns' concept of heterarchy and the organizational form of the Occupy Movement merits brief mention at this point so as to further emphasize their importance below. The contingent and provisional meritocratic qualities of this heterarchical arrangement of 'produsers' is fundamentally different than the hierarchical and rigid division of labour evident in the industrial or corporate sector.

Unwaged digital labourers, then, "lead by example, not by coercion, by merit, not by power inherited from a position in the hierarchy, by consensus, not by decree" (Bruns, 2008, 30). As the above description of the fundamentally autonomous nature of unwaged digital labour indicates, the potentials for this labour force to organize itself and its productive/creative capacities free of the wage relation is enormous. By overlooking this fundamental autonomy, we misjudge the present, though nascent, viability of form of organization that exists beyond the "negative externalities" characteristic of the capitalist relation. However, as the concept of autonomy and the cycles of struggle indicate, capital, a social relation dependent on the exploitation of others, will not slacken its grip without a fight.

The impetus behind these forms of networked struggle is often characterized as having to do with one's 'privacy' on networks that are eminently social. When considered from the perspective provided by the exploitative relationship between owners and labourers, in addition to considering the highly personal registers that absorb the brunt of this exploitative scenario, the second facet of unwaged digital labour is in need of further clarification.

\subsection{Facet Two: Hyper-Exploitation}

Without doubt, the "exploitation paradigm" is the facet that has been addressed most comprehensively by the academic literature regarding unwaged digital labour. The popularity of the "exploitation paradigm" is attributable to the long history of the communications and cultural industries and the manner in which they were, and remain, profitable enterprises. Based 
on the illuminating work of Dallas Smythe and his concept of the "Communications Blindspot" (1977), the modus operandi of corporate entities devoted to the business of media and communications has, despite tremendous alterations in the technologies of production, distribution, and reception, changed very little.

Well before the rise of the Internet, Smythe argued presciently that while the mass media produce copy, stories, images, films, photographs, and videos, they are primarily in the business of producing a commodity far more valuable than these trifling end products. First and foremost, communications industries old and new are in the business of producing and selling audiences. They bring these audience commodities to market so as to sell them to advertisers and marketers eager to ply their wares and services to eyeballs and intellects allegedly interested in the products/services on offer. While the copy, programming, dialogue, photographs, video, etc. are indeed end-products, they are, according to Smythe, but a 'free lunch' meant to entice a captive audience into consuming much more lucrative productsadvertisements and marketing appeals. Similar to the act of offering patrons at a pub free pretzels or peanuts in an attempt to whet their palates so that they might then consume a much more valuable commodity-alcohol primarily-the process of whetting the cognitive and emotive palates of media consumers with an array of 'free' stories or services that in turn then entice the consumption of much more valuable product, advertisements, media industries have long traded in the attention economy. The "audience commodity", however, is becoming ever more valuable as we move from an era defined by broadcasting to one dominated by narrowcasting, niche markets, the long tail, and "big data".

Numerous scholars have charted these developments. One of the most consequential, in terms of the transition from basic demographic research to much more finely tuned psychographic, behavioural, and bio-demographic research, is Mark Andrejevic. In a number of different texts, Andrejevic argues $(2002,2007,2009)$ that the development of more and more personalized media hardware and software has, at base, the intention of producing more and more accurate information regarding the specific predilections of an ever more refined audience commodity. Limiting his analysis to Digital Video Recorders (DVR) and couching his analysis in the Taylorist Paradigm of Scientific Management (Taylor 1915), Andrejevic argues that these digital contrivances are designed with the intention of tracking each and every television program the audience member views and/or records. He argues:

Even as it retrieves programming for viewers, the [DVR] doubles as a monitoring device in the service of the system's operators, creating a detailed 'time and motion' study of viewing habits that can be sold to advertisers and producers. In the panoptic register, the [DVR] becomes an automated confessional: an incitement to divulge the most intimate details of one's viewing habits. $(2002,240)$

By divulging the "most intimate details of one's viewing habits", the audience member is communicating a vast amount of information to a service provider regarding individualized preferences, patterns of consumption, and behavioural predispositions that can be crossreferenced with other demographic information such as location and average household income, so as to compile an accurate composite image of what this individual likes to watch, when s/he likes to watch it, where s/he is located, and how much disposable income s/he might have. This information is invaluable to media industries in that they can then offer their most valuable clients, advertisers, explicit information regarding the audience that is exposed to their commercial pleas.

If we extend this argument into the present day and age, as many of the most well regarded critical political economists of new media have done, what obtains is a composite profile of not only what a particular audience member likes to watch and when, but much, much more. Taking into consideration mobile communications, ubiquitous computing, "always-on" social networking, and the agglomeration of thousands of "likes", "+'s", and "retweets", advertisers not only get a sense of the consumptive patterns of the audience commodity, but are provided with a micro-detailed profile of every movement, purchase, 
habit, and location, in addition to the age, gender, and familial situation of this ever more unalloyed audiece commodity. An automated (digital) confessional indeed!

As mentioned, this situation is accurately described as exploitative. This is especially the case when the responsibility for generating all of the finely tuned information found on social media profiles falls to those same individuals who's attention is being bought and sold by the platforms upon which they labour. The work of Fuchs' is without question the most accurate and rightly acerbic in this regard. He believes that when 'users' begin generating content on Web 2.0 sites and services or data for search engines and, by doing so, generating value for the site,

\begin{abstract}
in terms of Marxian class theory, this means that they also produce surplus value and are exploited by capital as for Marx productive labour is labour generating surplus. Therefore the exploitation of surplus value in cases like Google, YouTube, MySpace, or Facebook is not merely accomplished by those who are employed by these corporations for programming, updating, and maintaining the soft- and hardware, performing marketing activities, and so on, but by wage labour and the producers who engage in the production of user-generated content. $(2009,30)$
\end{abstract}

In fact, according to Fuchs, this situation is better thought of as "one of infinite overexploitation [...] [or] an extreme form of exploitation" $(2011,298)$.

\title{
2.3. Facet Three: Resistance \& Struggle
}

Resistance to forms of exploitation is not unique to unwaged digital labour. However, the form of struggle that manifests within the unwaged digital domain is. For the most part, these struggles have been mischaracterized and, hence, misunderstood as pertaining to the violation of one's privacy. Whenever there is a controversy on a platform that exploits the unwaged digital labour of their "user" base, this controversy is misconstrued as one pertaining to the invasion of one's privacy. This mischaracterization has obfuscated a more accurate understanding of the registers at which this exploitation is experienced and, therefore, the forms of resistance that meet it. Once again, nomenclature is important in this regard.

For the most part, these instances of revolt are recurrently, simplistically, and myopically characterized as controversies pertaining to the invasion of one's 'privacy' on networks that are eminently social. Often, when a social network alters its Terms of Service (TOS) or its End User License Agreement (EULA) so as to extract more information and data from the profiles of a "user", there is resistance to these alterations. For instance, in December 2012, Instagram, a popular photo-sharing platform acquired by Facebook for US\$1 Billion (Raice and Ante, 2012), altered its Terms of Service in such a way that would allow them to sell the personal photographs of its members to advertisers. The member's, whose photograph or likeness would be portrayed in these advertisements, would receive no compensation for the use of said images. The images in question had already been uploaded to the service and were already being shared by these individuals. They were, then, anything but private. Therefore to characterize the ensuing outrage as pertaining to the violation of one's privacy is incorrect. Not surprisingly, Instagram's members resisted this form of exploitation and set about struggling against the changes to the social network's TOS. In an abrupt about-face, Instagram's owners withdrew their amended TOS (see Streitfeld and Perlroth 2012). This reversal further underscores the autonomy of peripatetic unwaged digital labourers and the fact that even in the era of social media, "Capital [...] needs labor. But labor does not need capital" (Dyer-Witheford 1999, 68).

Further evidence for resistance to (or struggles against) this form of exploitation would serve to bolster the claims made by theorists that subscribe to and defend the "exploitation paradigm". Brown (2013) provides such evidence by recasting the multiple instances of "user" uproar and revolt that have occurred, and will surely continue to occur, on Web 2.0 sites and services along more appropriate and accurate theortical lines than those associated with the violation of "user" privacy. However, "Privacy and social media are con- 
ceptually oxymoronic in that adherence to the principles of the former would render pointless the purposes and functionality of the latter" (Brown 2013, 386). Therefore, a more adequate and accurate explanation for the multiple instances of "user" uproar on Web 2.0 sites and services is one that takes into account the exploitative nature of these sites and services and the intimate registers at which this exploitation is experienced. Via recourse to Marx's ideas regarding "so-called primitive accumulation" (1976, 873-940) and Hardt and Negri's characterization of the exploitation of the personal and private moments of one's life as "biopolitical exploitation" $(2009,137)$, the author argues that:

\begin{abstract}
Privacy is inimical to the primary purpose of the networks themselves. These are spaces where individuals share personal moments openly and freely with friends and acquaintances that sometimes number in the thousands. In such realms, concern over privacy may be one way of understanding the kinds of protest and struggle that have taken place but [...] is not the best way. Much better at acknowledging the complexity of this context and the nuance of these struggles is the theoretical framework offered by reinterpretation of Marx's concept of primitive accumulation by way of Hardt and Negri's theory of biopolitical exploitation. (Brown 2013, 398)
\end{abstract}

In this way, when the personal relationships, intimate communicative practices, innermost affective responses, and interrelated social habits of individuals are exploited ever more completely, and "user's" gain an appreciation of these exploitative practices, they rightly (and via the channels they have become so adept at leveraging) vocalize their discontent and begin to reassert their autonomy. While the invasion of one's privacy is one way of understanding the multiple instances of uproar to have occurred on Web 2.0 sites and services, it is not the most accurate. Instead, understanding these instances of uproar as stemming from the biopolitical exploitation of members' affective relations is a more nuanced and appropriate explanation. Therefore, it is not only the presence of the exploitative social relationship that exists between owners and "users", but also resistance to this biopolitical form of exploitation that targets the highly collaborative and cooperative social relationships obtaining between "users" themselves.

\title{
2.4. Facet Four: Collaborative, Cooperative, Communicative \& Communal
}

Unwaged digital labour is inherently cooperative, collaborative, communal and based predominantly on the non-instrumental sharing of digitized content and data between members of Web 2.0 sites and services. Thus, the fourth facet of Unwaged Digital Labour that marks it as a distinct typological category is, on the surface, similar to that which distinguishes waged digital (or immaterial) labour, yet fundamentally different than that which commands and controls one's intimate communicative capacities from above. Lazzarato argues that waged digital labour, what he terms immaterial labour, "produces first and foremost a 'social relationship'" and that it "constitutes itself in forms that are immediately collective" (Lazzarato 1996, 136). Terranova extends the argument put forth by Lazzarato by applying the collective, social, and collaborative nature of waged digital labour to the unwaged realm. She argues:

Unrestricted by physical distance, [unwaged digital labourers] collaborate with each other without the direct mediation of money and politics. Unconcerned about copyright, they give and receive information without thought of payment. In the absence of states or markets to mediate social bonds, network communities are instead formed through mutual obligations created by gifts of time and ideas. (Terranova 2000, 36)

The fundamental difference being, then, that in a situation such as that described by Lazzarato, where the labourer exchanges his or her communicative, affective, and emotive capacities for a wage, "we have here a discourse that is authoritarian: one has to express oneself, one has to speak, communicate, cooperate, and so forth. The 'tone' is that of the people who were in executive command under Taylorization: all that has changed is the content" (Lazzarato 1996, 134). With unwaged digital labour, however, one does not have to do anything. The willingness and eagerness to communicate, collaborate, cooperate, and share 
with others is one that marks "unwaged digital labour" as distinct from its typological and waged predecessor. Members of Web 2.0 sites and services devote vast amounts of time, energy, and emotion to their social network of choice. They collaborate, cooperate, and communicate free of the wage relation, free of any kind of management oversight or supervisory directive, and are responsible for fostering and nurturing a community of peers in such a way that escapes this kind of top-down command and control. This, then, is what differentiates unwaged digital labour and its collaborative, cooperative, communicative and communal qualities from its waged variation.

Don Tapscott and Anthony Williams marvel at the self-organizing and collaborative capacities of unwaged digital labourers, albeit from an ideological position that runs counter to the argument presented herein. Referencing Flickr, a massive photo-sharing social network and early poster-child of the Web 2.0 environment, the authors argue that the owners of Flickr may provide,

\begin{abstract}
the basic technology platform and free hosting for photos [...] Users do everything else. For example, users add all of the content (the photos and captions). They create their own self-organizing classification system for the site (by tagging photos with descriptive labels). They even build most of the applications that members use to access, upload, manipulate, and share their content [...] Flickr is basically a massive self-organizing community of photo lovers that congregates on an open platform to provide its own entertainment, tools, and services. (Tapscott and Williams 2006, 38; emphasis added)
\end{abstract}

The cooperation, collaboration, and non-instrumental sharing immanent to Web 2.0 sites and services is formative of social relations and, thus, as will be discussed in the following section, forms of subjectivity, that allow us to glimpse, even if ever so slightly, the possibility of reorienting our infinitely creative and fundamentally autonomous labouring capacities beyond the exploitation and affective violence immanent to waged digital labouring practices. It is the fundamental autonomy of a self-organizing amalgam of highly cooperative, collaborative, communicative, and communally oriented peers spread throughout the global network, that often work on projects of amazing complexity free of the wage relation and free of any kind of management oversight that distinguishes unwaged digital labour from waged digital labour.

\title{
2.5. Facet Five: The Biopolitical Dimensions of Unwaged Digital Labour
}

The fifth facet of unwaged digital labour is arguably its most significant, certainly its most theoretically complex, and will therefore be examined in more depth of detail than those discussed above. Succinctly, unwaged digital labour is biopolitical. More comprehensively, unwaged digital labour requisitions and activates some of the most personal and intimate faculties of the individual that undertakes and accomplishes it. Over time and through exposure to the autonomous modes of unremunerated cooperation and collaboration that are the prerequisites to participation on these networks of affiliation, the subjectivity of the individual (in communion with the collective) is altered in biopolitically significant ways.

Michel Foucault coined the terms "biopower" and "biopolitics" (1978) in an attempt to provide a more subtle understanding of the myriad relationships of power that discipline and control the production and regulation of individual and collective subjectivity. Less obvious than monarchical power, more subdued than the power of the State and its various 'apparatuses' (Althusser 1971), biopower and biopolitics describe the constitutive influence of a variety of dispositifs (Delueze 1992), apparatuses (Agamben 2009), or biopolitical "machines" (Foucault 1995, 207) on our subjective dimensions. This kind of power over the individual and collective bios (and the political dimensions thereof) discipline and control the actions, behaviours, belief systems, and desires of the individual and collective in such a way that is not immediately apparent, nor recognizable. The various dispositifs, apparatuses, or machines of the biopolitical production of subjectivity arrange "things in such a way that the exercise of power is not added on from the outside, like a rigid, heavy constraint [...] but is so subtly present in them as to increase their efficiency" (Foucault 1995, 206) 
Foucault's most celebrated examples of biopolitical dispositifs, apparatuses, or machines are, of course, the architectural arrangement of light, brick, and glass characteristic of Bentham's panoptic prison, the discourse surrounding sexuality, and the classificatory function of psychiatric institutions. According to Foucault, biopower relies not on physical "force to constrain the convict to good behaviour, the madman to calm, the worker to work, the schoolboy to application, [nor] the patient to observation of the regulations" (Foucault 1995, 202), but on much more diffuse and nascent forms of suasion that discipline and control its subjects as if from the interior. In an infamous description, under regimes of biopower, the relationships of power that produce and regulate our subjective dimensions become "capillary" (Foucault 1980,96 ). Extending this idea into the contemporary era (and in light of the modifications to have taken place at the level of our digital labouring capacities) they have also become neuronal.

There exist a plenitude of biopolitical dispositifs, apparatuses, or machines in addition to those of the prison, the discourse characteristic of eighteenth century sexuality, and/or the psychiatric institution. Each has a consequential influence on the production and regulation of subjectivity. The most important of which, for the present purposes at least, is the biopolitical dimension of digital labour in general and unwaged digital labour in particular. According to Lazzarato, in the opening salvo of what has become, as this special edition of this journal indicates, one of the most hotly contested concepts in academia, waged "immaterial labour" (or what is more accurately referred to throughout this paper as "waged digital labour") is productive of subjectivity and thus can be considered, by extension, biopolitical. In a passage that speaks to the biopolitical impact of waged digital labour without naming it, Lazzarato argues: "[t]he concept of immaterial[/digital] labor presupposes and results in an enlargement of productive cooperation that even includes the production and reproduction of communication and hence of its most important contents: subjectivity." He continues,

[w] hat modern management techniques are looking for is 'the worker's soul to become part of the factory.' The worker's personality and subjectivity have to be made susceptible to organization and command [...] [and] [t]he capitalist needs to find an unmediated way of establishing command over subjectivity itself; the prescription and definition of tasks transforms into a prescription of subjectivities. (Lazzarato 1996, 134)

Making more complex Lazzarato's work, Michael Hardt and Antonio Negri make explicit the link between Foucault's concept of the 'biopolitical' and Lazzarato's argument regarding the subjective dimensions of immaterial/digital labour by claiming that 'waged immaterial/digital labour' is biopolitical. Waged digital labour is,

biopolitical in that it is oriented toward the creation of forms of social life; such labor, then, tends no longer to be limited to the economic but also becomes immediately a social, cultural, and political force. Ultimately, [...] the production involved here is the production of subjectivity, the creation and reproduction of new subjectivities in society. Who we are, how we view the world, how we interact with each other are all created through this social, biopolitical production" (2004, 66; emphasis in original).

In Commonwealth (2009), the authors go so far as to rename "immaterial labour", "biopolitical labour" in an attempt to emphasize its influence of the subjectivities of those who exchange their communicative and cooperative capacities for a wage. In other words, waged digital labour is biopolitical in that it requisitions, purchases, and, over time and through exposure, eventually commandeers one's ability to communicate and cooperate with others. As a result of the personal, affective, and communicative faculties, aptitudes, and talents this kind of work requisitions and progressively comes to control, the subjectivity of those individuals tasked with undertaking and accomplishing it is progressively colonized by the demands and dictates of those persons who have purchased the right to control it via the wage relation. By being forced to repeatedly communicate in the service of someone else, build personal and social relationships premised on the needs and desires of one's superior, conjure ideas, images, and affects that attend to the will of one's boss, and, thus, progressively ex- 
change control over these subjective capacities for a wage, the subjectivity of the worker is ever-more, though not entirely, overtaken by the needs, wants, and desires of their bosses. This kind of labour, then, is eminently biopolitical in that it purchases, commandeers, and regulates some of the most intimately subjective capacities of the individual as if from the interior. The pivotal point not addressed by the body of literature regarding the biopolitics of digital labour in general, however, is that its unwaged variant too is also biopolitical and constitutive of different forms of subjectivity than that of its waged genus. These different forms of subjectivity result from fundamentally different political economic relationships that exist between members of Web 2.0 sites and services themselves, rather than those that exist between waged digital labourers and their superiors.

Based on a fundamentally autonomous mode of digital production that is heterarchical, highly cooperative, collaborative, and founded on the non-instrumental sharing of the fruits of one's unwaged digital labour, the biopolitics of this same labour have opened up a space in our individual and collective consciousnesses that recalibrates "[w] ho we are, how we view the world, [and] how we interact with each other" (Hardt and Negri 2004, 66). The elemental autonomy of the unwaged digital labour taking place on and within these self-organized, selfmanaged, and self-regulated networks of affinity and recognition, passes the subjectivities of those individuals who populate, navigate, and participate in them through a different die. By doing so, they extrude a different form of subjectivity than that present prior to their appearance. This fundamentally autonomous amalgamation of individuals that come together on distributed networks that are, for all intents and purposes, leaderless, heterarchical, selfmanaged, and self-organized, open up a field of cognitive possibility that heretofore was deemed all but impossible. In doing so, they have posited the nascent feasibility of an organization of labouring bodies and minds, working in all corners of the globe, and free of the wage relation. The biopolitical force of unwaged digital labour is such, then, that it cracks the seemingly impenetrable veneer of the ostensible permanence and ahistorical nature of the hierarchical capitalist organization of life, love, and limb.

Possibilities that were inconceivable a few short years ago no longer seem absurd. Potentialities that at one time could not be dreamt appear attainable. Latencies that, in the past, may have remained as such, are thrust to fore and allowed the opportunity to prove their viability. If the biopolitical mechanisms of previous institutional and organizational forms moulded, disciplined (Foucault 1995) and controlled (Delueze 1992) the subjective dimensions of the individual and collective, then new biopolitical mechanisms have the potential to mould entirely different subjects. It is, then, the cognitive dimensions unlatched by the particular biopolitical mechanisms of unwaged digital labour that structure a new field of possibility and make viable a mode of social organization considered unimaginable a few short years ago.

One of the most consequential biopolitical dimensions of unwaged digital labour, therefore, is that it is based on a fundamentally different mode of production that comes to influence the subjectivities of those exposed to it. Referencing Marx, Jason Read argues:

The immanent relation between production and the production of subjectivity announces itself most forcefully at the points in Marx's writing where he deals with the problem of a transition from one mode of production to another. At these points of historical transformation, where one mode of production is destroyed and another is constituted, Marx underscores that such a transformation is impossible without a corresponding transformation of subjectivity. (Read 2002, 131)

He continues, arguing "Reproduction of a social relation is also reproduction of a particular form of subjectivity" (Read 2002, 134). The social relations that exist between members of Web 2.0 sites and services themselves are of a different type and kind than those that exist between owners and members. While others have dealt with the exploitative dimensions of the latter relationships, it is the forms of subjectivity produced by the former that are of particular interest. 
The biopolitics of unwaged digital labour have opened up "a whole field of responses, reactions, results, and possible inventions" (Foucault 1982, 789) that heretofore were never deemed viable. They have subtly rediscovered cognitive, communicative, and affective spaces from which we have begun to imagine new forms of heterogeneously collective, commons-based, and autonomous forms of self-organization and direction. It merits acknowledging that this unapologetically optimistic account of the biopolitical dimensions of unwaged digital labour is not without its sceptics or detractors. There are those who regard social media as emblematic of the further entrenchment of a neo-liberal subjectivity that forces users to self-brand (Hearn 2008) and market themselves as a commodity to others. Alice Marwick, for instance, argues that members of Web 2.0 sites and services "tend to adopt a neoliberal subjectivity that applies market principles to how they think about themselves, interact with others, and display their identities" $(2013,7)$. While these perspectives are important to acknowledge, they approach their object from a vantage point that does not take into account the biopolitical influence of the fundamental autonomy of unwaged digital labour and the evidence provided by another, equally important, set of evidentiary instances.

In an attempt to engage in this important debate, what follows will provide evidence for the impact of the biopolitical dimensions of unwaged immaterial labour on individual and collective subjectivity beyond that which regards it as nothing more than another incursion of neoliberalism into the subjective dimensions of individuals and collectives. This evidence can be found in nascent form within the organizational and communicative spaces leveraged by the multitudinous social movements that burst onto the global stage in 2011 and 2012.

\section{Audacious Imaginings}

In response to the Occupy Movement and the events of the "Arab Spring", Hardt and Negri published Declaration (2012). In the final paragraph of this text, the authors address one of the most consistent and (for some) confounding aspects of these diverse and heterogeneous movements: their apparent disorganization and the putative weaknesses associated with a leaderless movement that lacks a coherent and consistent set of sound-bite-friendly demands or purposes. Taking into consideration the different organizational forms adopted by these movements, Hardt and Negri write:

Don't think that the lack of leaders and of a party ideological line means anarchy, if by anarchy you mean chaos, bedlam, and pandemonium. What a tragic lack of political imagination to think that leaders and centralized structures are the only way to organize effective political projects! (Hardt and Negri 2012, 91)

However, the 'tragic lack of political imagination' associated with regarding a fundamentally heterogeneous and leaderless movement as somehow anarchic, confused, or disorganized, has begun to give way in light of the biopolitical force of unwaged digital labour and the evidentiary feasibility of such associative forms made manifest via the channels of social media and Web 2.0 sites and services. The experience of labouring on autonomous networks of loose affiliation based on heterarchical modes of organization and production "falls back on the process" (Read 2002, 115) and in so doing unhinges the bung on an anything-but-tragic imagination that can perhaps (for the first time) glimpse the feasibility of such an audacious prospect. Put simply, the biopolitics of unwaged digital labour make possible thoughts and imaginings regarding 'a whole field of responses, reactions, results, and possible inventions' that in the past might never have been considered.

The primary argument that this paper has been leading up to is the following. The biopolitical dimensions of unwaged digital labour posit the nascent viability and latent feasibility of a fundamentally autonomous and heterogeneous organization of individuals that remain as such within a collective. They have, in a manner of speaking, freed the imagination of these same individuals regarding the capacity to organize themselves and their creative capacities in a similar fashion in the material world. Dyer-Witheford argues correctly that "It is nothing if not audacious to discern" $(1999,87)$ such a composition of heterogeneous individuals, movements, and alliances, but it is becoming ever less so as a result of the experience and 
biopolitical force of just such an affinity of alliances made and fostered via unwaged digital labouring practices.

According to Jason Read in a passage referring specifically to the changed mode of production characteristic of waged digital labour:

Mutation of the [mode of production] does not simply alter what can be produced, or how, but it falls back on the process, transforming the producer himself or herself. The production of things is also always an autopoieis, a production of the one producing-a production of subjectivity. As Marx writes with respect to the laborer, 'Through this movement he acts upon external nature and changes it, and in this way he simultaneously changes his own nature.' (2003, 115; emphasis added)

The fundamental point being, once again, that we must not limit the application of this theoretical observation too narrowly to the point that it applies exclusively to the waged digital labouring environment. Rather,

we should keep an eye out from the beginning, following Foucault's intuition, for how biopolitical production, particularly in the ways it exceeds the bounds of capitalist relations constantly refers to the common, grants labor increasing autonomy and provides the tools or weapons that could be wielded in a project of liberation. (Hardt and Negri 2009, 137)

In this manner, we need to regard all of the unwaged digital labour taking place on Web 2.0 sites and services as an elementary stage in fashioning the organizational, cognitive, and affective "tools or weapons that could be wielded in a project of liberation".

The radical experimentations with direct democracy and leaderless modes of organization undertaken by a variety of social movements the world over, which on their surface are, indeed, "nothing if not audacious", are made less so because of the experience of activists (and the public at large!) on social media sites and services accustomed to exactly this kind of (dis)organizational environment. The ostensible impossibility of a leaderless organization of heterogeneous and autonomous individuals is, therefore, made much less so as a result of the experiences of activists, protestors, and the public at large on Web 2.0 sites and services. The biopolitics that guide and regulate the production and regulation of subjectivity, that act upon the present or future actions of these same participants, have escaped their virtual confines and have come to influence a jubilant imagination that dares to dream beyond the cybernetic sphere.

The ray of hope shone by the significance of the encounters that individuals have with the various biopolitical dispositifs, apparatuses, or machines that fashion and refashion their subjectivities is that they are in a perpetual process of becoming something and someone other than that which they presently are. According to Hardt and Negri, "The most important fact about human nature (if we still want to call it that) is that it can be and is constantly being transformed" $(2009,191)$. At base, subjectivity and 'human nature' are, then, historical. This fact postulates a malleable subject, one that is in a constant process of change, influenced by the biopolitical "machines" through which s/he passes. According to Read, "transformations in technology, politics, media, and the economy affect each other insofar as they produce new subjectivities and new relations" $(2001,28)$. The importance of this realization is that the transformations evinced by the technologies and social relations emblematic of Web 2.0 "produce new subjectivities and new relations" that inform the means by which we may become something other, indeed something much better, than that which we presently are. Our world, then, "is continually made and remade by the bodies and desires of the many, thus exposing the way in which the world can be made otherwise" $(2001,30)$.

This shift in thinking towards a possible or future self is consequential in that "Once the temporal horizon of a possible future replaces the spatial confines of an existing sphere [...], the standard by which the present is judged could expand to visions of what we might want rather than the defense of what we already have, know, or are" (Weeks 2007, 248). In other words, "Through the production of subjectivity, the multitude is itself author of its perpetual becoming other, an uninterrupted process of collective self-transformation" (Hardt and Negri 
$2009,173)$ that is influenced in a consequential fashion by the experiences and modes of autonomous production characteristic of unwaged digital labour. It is not only that the biopolitics of unwaged digital labour 'fall back upon the process,' then, it is that they provide subtle evidence of a differential mode of existence made manifest in the audacious and jubilant imagination that briefly exerted itself in the global wave of revolt and struggle witnessed in 2011 and 2012.

\section{Conclusion: Audacity Unhinged}

In the fall of 2011, a wave of protests and Occupy Movements that began in Zucotti Park in New York City quickly spread around the world. The demands of these movements were diverse and their goals and tactics equally so, but the variegated forms of inequity and widespread lack of opportunity they were railing against, all too common. Drawing inspiration from the struggles in Egypt, Libya, and Syria, the student protests in the United Kingdom, the antiausterity movements in Greece, the struggles of the Spanish Indignados, and the complete lack of culpability placed at the feet of those persons responsible for the worst Global Financial Crisis (GFC) in world history, the Occupy Movement was concrete evidence that the recomposition of a 'class' hostile to imperial capital was beginning to take embryonic form.

At the technological epicentre of this movement were a number of social networks that enabled the transmission and receipt of digitized messages, photographs, and video. With the so-called "Twitter Revolution" in Tunisia (Zuckerman, 2011), the role of BlackBerry's Messenger application in the student riots in London (Wasik, 2011), and the place of Facebook in Egypt's Tahrir Square, not to mention the "99\%'s" tumblr blog, the relative importance of social networks and communication technologies to forms of struggle and resistance is a hotly debated topic. This paper has no interest in engaging with the argument regarding whether or not these were "Twitter Revolutions" or "Facebook Revolutions". What it is interested in is better understanding the manner in which the biopolitical dimensions of all the unwaged digital labour taking place on these networks has "fallen back on the process" and produced forms of subjectivity that no longer dismiss the feasibility of a leaderless, heterarchical, and unapologetically heterogeneous movement as a practical impossibility. Social networks like Twitter or Facebook, therefore, should not be thought of as determining factors in these struggles, but as dispositifs, apparatuses, or "biopolitical machines" endowed with particular affordances that work upon the subjectivities of those persons who daily use them. In other words, these technologies have not and could never change the world on their own, but, paraphrasing Marcuse $(1978,32-33)$, the biopolitical dimensions of all the unwaged digital labour required to use them are in the process of changing the subjectivities of those individuals who could.

According to a number of different academics, it is at the biopolitical level of the constitution of subjectivity that one of the most important forms of contemporary struggle is focused. For instance, Hardt and Negri, "regard the production of subjectivity [...] as the primary terrain on which political struggle takes place. [They argue,] We need to intervene in the circuits of the production of subjectivity, free from the apparatuses of control, and construct the bases for an autonomous production." (Hardt and Negri 2009, 172). Later on in the same text, they reiterate, "liberation [...] requires engaging and taking control of the production of subjectivity" (Hardt and Negri 2009, 331-332). David Harvey, too, agrees. In an otherwise less than glowing review of Commonwealth, Harvey writes:

Its authors are unquestionably right, for instance, to insist that critical engagement with how subjects and subjectivities are produced is essential if we are to understand revolutionary possibilities and that is something classical Marxism was not adept enough at doing. [...] And they constructively take up Foucault's notion of dispositifs as 'the material, social, affective, and cognitive mechanisms in the production of subjectivity.' Doing so, Hardt and Negri say, 'allows us to conceive the collective production of the common as an intervention in the current relations of force aimed at subverting the dominant powers and reorienting forces in a determinate direction. The strategic production of knowledge 
in this sense implies an alternative production of subjectivity.' And this is where their theory of revolution comes from. (Harvey, Hardt and Negri 2009, 4-5)

Jason Read offers a more succinct variation of the above argument, but he does so by considering the influence of waged digital labour on the production of subjectivity. He argues that,

the stakes of opposing capital are not simply economic or political, but involve the production of subjectivity. In order to oppose capital it will be necessary to engage in a counter production of subjectivity. The tools for this counter-production are already in our hands, in the affective and communicative networks that are created and maintained in our day to day labors. $(2002,141)$

Via an examination of the four-facets of unwaged digital labour in general offered above and a more focused investigation into the biopolitical dimensions of unwaged digital labour in particular, this paper provides a more detailed and nuanced examination of one of the more consequential apparatuses responsible for the production and regulation of a form of subjectivity not only hostile to the 'negative externalities' of neo-liberal capital, but amenable to and capable of imagining a fundamentally different way of organizing individuals and collectives free of said negative externalities.

The audacious and jubilant imagination of a group of autonomous individuals accustomed to heterarchical modes of leaderless self-organization took its first infant steps in 2011 and 2012, then very quickly came crashing to the ground. The knowledge, courage, and strength to take these initial steps, however, did not arise from, nor vanish into, the abyss. Nor did the oppression, violence, and inequality these struggles were railing against. While Web 2.0 sites and services like Facebook and Twitter are often mistakenly characterized as the pivotal implements that brought down the oppressive Gaddafi and Mubarak regimes, for instance, this perspective fails to acknowledge the resolute efforts of the individuals who together fought, suffered, and, in some instances, perished in these struggles. Twitter has never caused a revolution. Neither has Facebook. However, the biopolitics of the unwaged digital labour performed on these networks produce forms of individual and collective subjectivity daring enough to make the demands they did. The viability of just such an amalgam of heterogeneous actors that gathered in virtual and material spaces in an attempt to autonomously organize their infinitely creative capacities was, in the not too distant past, all but inconceivable. Today, however, it has become less so and the struggles that will without question continue are more potent and powerful because of it.

\section{References}

Agamben, Giorgio. 2009. What Is An Apparatus?-And Other Essays. Stanford, California: Stanford University Press.

Althusser, Louis. 1971. Lenin and Philosophy, and Other Essays. Translated by Ben Brewster. London: New Left Books.

Andrejevic, Mark. 2002. The Work of Being Watched: Interactive Media and the Exploitation of SelfDisclosure. Critical Studies in Media Communication 19 (2): 230-248.

Andrejevic, Mark. 2007. Surveillance in the Digital Enclosure. The Communication Review 10 (4): 295-317.

Andrejevic, Mark. 2009. Exploiting Youtube: Contradictions of User-Generated Labour. In The YouTube Reader, edited by Pelle Snickers and Patrick Vondreau, 406-423. Stockholm: National Library of Sweden.

Berardi, Franco. 2009. The Soul At Work: From Alienation to Autonomy. Los Angeles: Semiotext(e).

Brown, Brian A. 2013. Primitive Digital Accumulation: Privacy, Social Networks \& Biopolitical Exploitation. Rethinking Marxism 25 (3): 385-403.

Brown, Brian A. and Anabel Quan-Haase. 2012. A Workers' Inquiry 2.0. tripleC-Communication, Cognition, Cooperation 10 (2): 488-508.

Bruns, Axel. 2008. Blogs, Wikipedia, Second Life, and Beyond: From Production to Produsage. New York: Peter Lang. 
Bruns, Axel. 2007. Produsage: Necessary Preconditions. Produsage. Accessed May 13, 2014. http://produsage.org/node/12

Cohen, Nicole. 2008. The Valorization of Surveillance: Towards a Political Economy of Facebook. Democratic Communique: Journal for the Union of Democratic Communications 22 (1): 5-22.

Coté, Marc, and Jennifer Pybus. 2007. Learning to Immaterial Labor 2.0: MySpace and Social Networks. Ephemera: Theory and Politics in Organization 7 (1): 88-106.

Coté, Marc, and Jennifer Pybus. 2011. Learning to Immaterial Labour 2.0: Facebook and Social Networks. In Cognitive Capitalism, Education and Digital Labor, edited by Michael A. and Ergin, Bulut Peters. New York: Peter Lang.

Dalla Costa, Mariarosa, and Selma James. 1973. The Power of Women and the Subversion of Community. Bristol: Falling Wall Press.

Delueze, Gilles. 1992. Poscript on the Societies of Control. OCTOBER 59 (Winter 1992): 3-7.

Deleuze, Gilles. 2007. What is a Dispositifs? In Two Regimes of Madness: Texts and Interviews, 1975-1995, by Gilles Deleuze and D. Lapoujade. New York: Semiotext(e).

Dyer-Witheford, Nick. 1999. Cyber-Marx: Cycles and Circuits of Struggle in High-Technology Capitalism. Urbana, III.: University of Illinois Press.

Foucault, Michel. 1978. The History of Sexuality. Vol. 1. New York: Vintage Books.

Foucault, Michel. 1980. Power/Knowledge: selected interviews and other writings 1972-1977. Edited by Colin Gordon. Translated by Colin Gordon, Leo Marshall, Leo Mepham and Kate Soper. New York: Pantheon Books.

Foucault, Michel. 1982. The Subject and Power. Critical Inquiry 8 (4): 777-795.

Foucault, Michel. 1995. Discipline and Punish: The Birth of the Prison. New York: Vintage Books.

Frier, Sarah, and Leslie Picker. 2013. Twitter Stays Mum on Profit on Roadshow Ahead of IPO.

Bloomberg. Accessed May 13, 2014. www.bloomberg.com/news/2013-10-31/twitter-stays-mum-onprofit-on-roadshow-ahead-of-ipo.html

Fuchs, Christian. 2009. Social Networking Sites and the Surveillance Society. Vienna: Forschungsgruppe. Online edition: http://fuchs.icts.sbg.ac.at/SNS_Surveillance_Fuchs.pdf.

Fuchs, Christian. 2010. Labor in informational capitalism and on the internet. The Information Society 26 (3): 179-196.

Fuchs, Christian. 2011. Web 2.0, Prosumption, and Surveillance. Surveillance and Society 8 (3): 288309.

Fuchs, Christian. 2012. Dallas Smythe Today-The Audience Commodity, the Digital Labour Debate, Marxist Political Economy and Critical Theory. Prolegomena to a Digital Labour Theory of Value. tripleC_Communication, Capitalism \& Critique 10 (2): 692-740.

Fuchs, Christian. 2012. Google Capitalism. tripleC_Communication, Capitalism \& Critique 10 (1): 4248.

Fuchs, Christian, and Sebastian Sevignani. 2013. What is Digital Labour? What is Digital Work? What's Their Difference? And Why Do These Questions Matter for Understanding Social Media? tripleC_Communication, Capitalism \& Critique 11 (2): 237-293.

Hardt, Michael and Antonio Negri. 2000. Empire. Cambridge, MA: Harvard University Press.

Hardt, Michael and Antonio Negri. 2004. Multitude: War and Democracy in the Age of Empire. New York: Penguin Press.

Hardt, Michael and Antonio Negri. 2009. Commonwealth. Cambridge, MA: The Belknap Press of Harvard University Press.

Hardt, Michael and Antonio Negri. 2012. Declaration. e-book: Argo-Navis.

Harvey, David, Michael Hardt, and Antonio Negri. 2009. Commonwealth: An Exchange. Artforum International (November): $210+$.

Huws, Ursula. 2003. The Making of a Cybertariat: Virtual Work in a Real World. London: Merlin.

Kleiner, Dmytri and Brian Wyrick. 2007. InfoEnclosure 2.0. Metamute. Accessed May 13, 2014. http://www.metamute.org/en/InfoEnclosure-2.0

Lazzarato, Maurizio. 1996. Immaterial Labor. In Radical Thought in Italy: A Potential Politics, edited by Paolo Virno and Michael Hardt, 133-147. Minneapolis, Minnesota: University of Minnesota Press.

MacroAxis. Ford Number of Employees. Macroaxis. November 22, 2013. http://www.macroaxis.com/invest/ratio/F--Number of Employees .

Marcuse, Herbert. 1978. The Aesthetic Dimension. Boston: Beacon Press.

Marx, Karl. 1976. Capital: Volume 1. New York: Penguin Classics.

Marx, Karl. 1975. Marx and Engles Collected Works. Translated by Ben Fowkes. Vol. 34. New York: Intl Publishers. 
Negri, Antonio. 1989. The Politics of Subversion: A Manifesto for the Twenty-First Century. Oxford: Polity Press.

Negri, Antonio. 1991. Marx Beyond Marx: Lessons on the Grundrisse. Brookly, N.Y. : Autonomedia.

O'Reilly, Tim. 2005. What is Web 2.0? Design Patterns and Business Models for the Next Generation of Software. O'Reilly. Accessed May 13, 2014. http://oreilly.com/web2/archive/what-is-web-20.html

Raice, Shayndi and Spencer Ante. 2012. Insta-Rich: \$1 Billion for Instagram. Wall Street Journal. April 10, 2012: B1.

Read, Jason. 2001. The Hidden Abode of Biopolitical Production: Empire and the Ontology of Production. Rethinking Marxism 13 (3/4): 24-30.

Read, Jason. 2002. A Fugitive Thread: The Production of Subjectivity in Marx. Pli 13: 125-146.

Read, Jason. 2003. The Micro-Politics of Capital: Marx and the Pre-History of the Present. Albany, New York: State University of New York Press.

Rushe, Dominic. 2011. Myspace Sold for \$35m in Spectacular Fall from \$12bn Heyday. The Guardian. Accessed May 13, 2014. http://www.theguardian.com/technology/2011/jun/30/myspacesold-35-million-news

Rushe, Dominic. 2013. US CEOs Break Pay Record as Top 10 Earners Take Home At Least $\$ 100 m$ Each. The Guardian. Accessed May 13, 2014. http://www.theguardian.com/business/2013/oct/22/top-earning-ceos-100m-paychecks-record

Smythe, Dallas. 1977. Communications: Blindspot of Western Marxism. Canadian Journal of Political and Social Theory 1 (3): 1-28.

Streitfeld, David and Nicole Perlroth. 2012. Instagram Reversal Doesn't Appease Everyone. New York Times. December 22, 2012: B1.

Taylor, Fredrick Winslow. 1915. The Principles of Scientific Management. New York: Harper \& Brothers.

Terranova, Tiziana. 2000. Free Labor: Producing Culture For the Digital Economy. Social Text 18 (2).

Turkle, Sherry. 2011. Alone Together: Why We Expect More from Technology and Less from Each Other. New York: Basic Books.

Wages For Housework. 1988. Wages For Housework. New Internationalist Magazine. March 1988.

Weeks, Kathi. 2007. Life Within and Against Work: Affective Labor, Feminist Critique, and Post-Fordist Politics. Ephemera 7 (1): 233-249.

\section{About the Author}

Brian A. Brown

Brian A. Brown is an Assistant Professor in the Department of Communication, Media \& Film at The University of Windsor in Windsor, Ontario, Canada. His research and teaching are broadly focused on the progressive political potentials evinced by the rapid adoption and profusion of what can broadly be characterized as 'social' or 'new' media. 